\title{
Determinants of Erectile Dysfunction in Hemodialysis Patients in CNHU- HKM, Cotonou
}

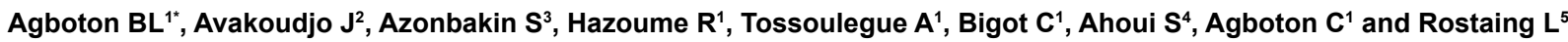 \\ ${ }^{1}$ Department of Medicine and Medical Specialties, University of Abomey-Calavi, Cotonou, Benin \\ ${ }^{2}$ Department of Surgery and Surgical Specialties, University of Abomey-Calavi, Cotonou, Benin \\ ${ }^{3}$ Department of Basic Sciences, University of Abomey-Calavi, Cotonou, Benin \\ ${ }^{4}$ Department of Medicine and Medical Specialties, University of Parakou, Parakou, Benin \\ ${ }^{5}$ Department of Nephrology, University of Grenogle Alpes, Grenogle, France
}

\section{Abstract}

Objective: The purpose of this study is to identify determinants of erectile dysfunction in hemodialysis patients in CNHU-HKM, Cotonou.

Method: It was a cross-sectional, descriptive and analytical study conducted over a period of six months, from $1^{\text {st }}$ March to $30^{\text {th }}$ August 2017. Prospective data collection was carried out, along with a comprehensive census of hemodialysis patients meeting inclusion criteria. Sexual function was assessed through full version of International Index of Erectile Function (IIEF).

Results: 114 hemodialysis patients were included in the study, with mean age estimated at 51.05 years \pm 11.66 . Among the study population, 100 patients $(87.7 \%)$ had hypertension as comorbidity, hypertensive Nephropathy $(67.5 \%)$ and Diabetic Nephropathy (14\%). The average duration on dialysis was $74.34 \pm 55.74$. Forty-three hemodialysis patients $(37.7 \%)$ were with depression, $56(49.1 \%)$ had lower testosterone, $38(33.3 \%)$ high rate of LH and $63(55.3 \%)$ high FSH. $98(86 \%)$ of them experienced erectile dysfunction, 97(85.1\%) sexual desire disorder and $80(70.2 \%)$ orgasm disorder. Determinants of erectile dysfunction in hemodialysis patients included age $(p<0.001 ; O R=1.168)$, hypertension $(p<0.001 ; O R=10,111)$, seniority in hemodialysis $(p=0.008 ; O R=1.024)$, depression $(p=0.022$; $\mathrm{OR}=11,250)$ and testosteronemia $(\mathrm{p}=0.038 ; \mathrm{OR}=0.740)$.

Conclusion: Sexual dysfunction prevalence is high in patients receiving dialysis. There is need to include care and support in these patient's treatment strategies.

Keywords: Determinants; Hemodialysis; Erectile dysfunction

\section{Introduction}

Chronic Kidney Disease (CKD) is a heavily debilitating disease characterized by the loss of kidneys major functions [1]. It is a global public health issue, particularly in developing countries. Best estimates in sub-Saharan Africa suggest that 12 to $23 \%$ of adults develop CKD [2], with admission prevalence estimated at $7.5 \%$ [3]. Sexual dysfunction is one of the complications of CKD. It is a real problem confronting the patient on daily basis, though often under-estimated by healthcare staff. This is partly due to the insignificant number of studies conducted on this disease and the patient's reluctance to discuss with the physician [4]. Male sexual dysfunction is defined by disorders in terms of erection, sexual desire, ejaculation and orgasm [5].

The frequency of these sexual disorders is amplified in CKD patients among whom it is estimated between $50 \%$ and $70 \%$, depending on the stage of kidney disease $[4,6,7]$. Half of end-stage CKD patients suffer from sexual disorders with reduced libido in association with impaired spermatogenesis [8]. Among these sexual disorders, erectile dysfunction (ED) was the most studied condition. Its prevalence during CKD is $49-55 \%[1,9]$.

Major advancement in healthcare for CKD patients in recent decades have resulted in rise in their life expectancy. So, at an advanced stage, a substitution treatment is required: "transplant" or "dialysis". The latter worsens pre-existing endocrine disorders and adversely affects the patient quality of life [8]. According to Nzibiti, in $75 \%$ of cases a patient's sexual life is affected after having received dialysis [10]. Sexual dysfunction prevalence rises from $9 \%$ to $60-70 \%$ after dialysis [11]. Hence, erectile dysfunction (ED) estimated at $9 \%$ in CKD patients not on dialysis is close to $90 \%$ in dialysis patients [6]. Organic factors such as endocrine disorders affecting the hypothalamic-pituitarygonad axis [10] and arterial disease specific of patients on dialysis [12] were revealed as well as risk factors: age, atherosclerosis, dialysis duration, and initial nephropathy [1]. The purpose of this study is to identify determinants of erectile dysfunction in hemodialysis patients in CNHU-HKM, Cotonou.

\section{Materials and Methods}

\section{Type of study and study population}

We carried out a cross-sectional, descriptive and analytical study from $1^{\text {st }}$ March to $30^{\text {th }}$ August 2017. The study population was made up of male hemodialysis patients seen in Nephrology-Hemodialysis Department of Hubert Koutoukou Maga Teaching Hospital (CNHUHKM), Cotonou.

\section{(a) Inclusion criteria \\ The followings were included in our study:}

*Corresponding author: Bruno Leopold Agboton, Faculty of Health Science, University of Abomey-Calavi, 01 BP 188 Cotonou, Benin, Tel: (00229) 97881017; E-mail: bruno_agboton02@yahoo.fr

Received: December 21, 2017; Accepted: December 24, 2017; Published: December 29, 2017

Citation: Agboton BL, Avakoudjo J, Azonbakin S, Hazoume R, Tossoulegue A, et al. (2017) Determinants of Erectile Dysfunction in Hemodialysis Patients in CNHU HKM, Cotonou. J Kidney 2: 159. doi: 10.4172/2472-1220.1000159

Copyright: (c) 2017 Agboton BL, et al. This is an open-access article distributed under the terms of the Creative Commons Attribution License, which permits unrestricted use, distribution, and reproduction in any medium, provided the original author and source are credited. 
Citation: Agboton BL, Avakoudjo J, Azonbakin S, Hazoume R, Tossoulegue A, et al. (2017) Determinants of Erectile Dysfunction in Hemodialysis Patients in CNHU-HKM, Cotonou. J Kidney 3: 159. doi: 10.4172/2472-1220.1000159

- Patients who have been on dialysis for at least 6 months prior to the evaluation.

- Male hemodialysis patients, from 18 to 80 years.

- Patients having given their informed consent to participate in the study.

\section{(b)Non-inclusion criteria}

Patients non-included in our study were those:

- On dialysis catheter.

- With trauma or pathology related to the spine and pelvis.

- Unable to provide responses to questions, or having mental disorders.

- Who did not give their consent.

\section{(c) Exclusion criteria}

- Patients who did not carry out biological examinations.

\section{Method and sampling technique}

We resorted to non-probabilistic sampling method with comprehensive census of all hemodialysis patients meeting the inclusion criteria.

\section{Variables and their operational aspects}

(a) Dependent variable: The dependent variable was sexual dysfunction. Sexual function was assessed through full version of International Index of Erectile Function (IIEF). It was validated as a convenient and reliable diagnosis tool for sexual dysfunction. IIEF includes 15 questions addressing five areas: Erection, orgasm, sexual desire, satisfaction with sexual intercourse and overall satisfaction. Answers to each question represent the patient experience in the last four weeks using a five-point scale. The score of an area: Erection, orgasm, sexual desire, satisfaction with sexual intercourse and overall satisfaction is obtained by summing the scores of answer provided for each question in the area (Table 1) [13].

\section{(b) Independent variables}

(i) Socio-demographic variables

- Age: Expressed in number of completed years of age and clustered by age-group.

- Marital status: Married/concubinage, single, divorced, widowed.

(ii) Medical-surgical history related variables

- History of pelvic trauma (pelvis and/or perineum)

\begin{tabular}{|l|c|c|c|c|c|}
\hline & \multicolumn{5}{|c|}{ Interpretation } \\
\hline Areas & Severe dysf. & $\begin{array}{c}\text { Moderate } \\
\text { dysf. }\end{array}$ & $\begin{array}{c}\text { Moderate to } \\
\text { light dysf. }\end{array}$ & $\begin{array}{c}\text { Light } \\
\text { dysf. }\end{array}$ & No dysf. \\
\hline Desire & $0-2$ & $3-4$ & $5-6$ & $7-8$ & $9-10$ \\
\hline Erection & $0-6$ & $7-12$ & $13-18$ & $19-24$ & $25-30$ \\
\hline Orgasm & $0-2$ & $3-4$ & $5-6$ & $7-8$ & $9-10$ \\
\hline $\begin{array}{l}\text { Satisfaction } \\
\text { with sexual } \\
\text { intercourse }\end{array}$ & $0-3$ & $4-6$ & $7-9$ & $10-12$ & $13-15$ \\
\hline $\begin{array}{l}\text { Overall } \\
\text { satisfaction }\end{array}$ & $0-2$ & $3-4$ & $5-6$ & $7-8$ & $9-10$ \\
\hline Dysf.- Dysfunction & & & & & \\
\hline
\end{tabular}

Table 1: IIEF interpretation.
- History of abdominal-pelvic surgery

- History of stroke

- History of exposure to ionizing radiation.

- Other conditions

(ii) Comorbidities related variables

- High blood pressure (HBP)

- Diabetes

- Peripheral neuropathy: Patients with dermal hypoesthesia, paraesthesia, burning feet and/or absent deep tendon reflexes were declared to have developed peripheral neuropathy.

- Congestive heart failure

- Prostatic hypertrophy

- Psychiatric pathology

(iii) Cardiovascular risk factors related variables

- Alcoholism: It was quantified in terms of number of grams of alcohol per day.

- Smoking: It was quantified in accordance with the number of sticks per day.

- Dyslipidemia: Matching one of the following anomalies:

- LDL cholesterol levels $\geq 1.5 \mathrm{~g} / \mathrm{l}$ or specific therapy ongoing

- HDL cholesterol levels $<0.40 \mathrm{~g} / \mathrm{l}$ or specific therapy ongoing

- Total cholesterol levels $>2 \mathrm{~g} / \mathrm{l}$ or specific therapy ongoing

- Triglycerides levels $>1.5 \mathrm{~g} / \mathrm{l}$ or specific therapy ongoing

(iv) Initial nephropathy related variable

- Diabetic nephropathy

- Nephroangiosclerosis

- Chronic glomerulonephritis

- Polycystic kidney disease

- Indeterminate or others

(v) Hemodialysis parameters related variables

- Seniority in hemodialysis (expressed in months)

- Frequency of hemodialysis sessions per week

(vi) Variable relating to high risk treatment of sexual dysfunction

- $\quad \beta$-blockers

- Central anti-hypertensive

- $\quad$ Cimetidine

- Neuroleptic medication

- $\quad$ Antidepressant (MAOIs, anti-cholinergic drug)

- Diuretic

- Hypolipidemic drugs

(vii) Depression

It was evaluated on the basis of Patient Health Questionnaire 
(PHQ). It is an evaluation tool for depression diagnosis. It includes 9 questions directly from the nine signs and symptoms of depression according to DSM-IV. Items 1 to 9 are rated on $0-3$ scale and item 10 (level of functioning) is rated on $0-4$ scale. A score ranging from 1 to 4 suggests absence of depression, 5 to 9 mild depression, 10 to 14 moderate depression, 15 to 19 moderately severe depression, 20 to 27 severe depression [14].

Sensitivity and specificity of PHQ is higher than those of other questionnaires of the same caliber [15,16].

\section{(viii) Physical examination related variables}

\section{- $\quad$ Nutritional status}

It was evaluated through calculation of Body Mass Index (BMI) on the basis of weight (expressed in $\mathrm{kg}$ ) and height (expressed in meters). The classification was elaborated as follows [17]:

Malnutrition: $\mathrm{BMI}<18.5$

Normal BMI: BMI between 18.5 and 25

Overweight: BMI between 25.1 and 30

Grade I overweight: BMI between 30.1 and 35

Grade II overweight: BMI between 35.1 and 40

Grade III overweight: BMI $\geq 40$

- Abdominal overweight: When waist size is greater than or equal to $102 \mathrm{~cm} \mathrm{[18].}$

- Secondary sexual features

- Gynecomastia

- $\quad$ Femoral pulse

- $\quad$ Femoral bruit

- External genitals examination

(ix) Hormonal parameters related variables

- Total testosterone

- $\quad$ Rate of $\mathrm{LH}$

- $\quad$ Rate of FSH

Blood sample was taken from each patient included in the study for $\mathrm{FSH}, \mathrm{LH}$ and testosterone competitive heterogeneous assays using a multiparameter device labelled Vidas ${ }^{\varpi}$ (Bio-Mérieux). The results of various exams were interpreted on the basis of usual values recorded in the case of an adult male considered as healthy:

- Total testosterone: $2,5-8.5 \mathrm{ng} / \mathrm{ml}$

- $\quad \mathrm{LH}: 1-8 \mathrm{mUI} / \mathrm{ml}$

- $\quad \mathrm{FSH}: 1-5 \mathrm{mUI} / \mathrm{ml}$

\section{Data collection, processing and analysis}

- Data collection was carried out via a standardized sheet

- $\quad$ Data collected were entered through EPI Data (version 3.5.1), then processed and analyzed with SPSS 23.

- Tables and graphs were developed with Excel 2013.

- $\chi^{2}$ independence test and $\mathrm{t}$ Student test were used for bivariate analysis. $\chi^{2}$ independence test enabled to search the relationship between two qualitative variables while t Student test allowed to establish a bivariate relationship between a metric variable and a non-metric variable. For these tests, a probability $\mathrm{p}<0.05$ was considered statistically significant.

- Logistic regression was used to quantify the strength of the association between each independent variable and the dependent variable represented by sexual dysfunction. The coefficients estimated by this model are mathematically related to odds-ratio which represents the strength of the association between a factor and a disease, although it is only an estimate of the relative risk.

This study, carried out as part of academic work, was in strict compliance with the principles of good clinical practices (GCP). Patients gave their free and informed written consent. Confidentiality was strictly maintained during data collection. The information obtained as part of this study was processed in complete anonymity. The results from the different analyses were transmitted to the physician for the benefit of patients.

\section{Results}

Patients with sexual dysfunction were selected on the basis of abnormal score in at least one of the IIEF areas. Table 1 highlights the IIEF interpretation. At the end of our survey, 114 male hemodialysis patients were selected.

\section{Socio-demographic characteristics}

(a) Age: The respondents mean age was 51.05 years \pm 11.66 with extremes values of 24 and 75 years. $46-55$ years age group was the most represented (33.33\%).

(b) Marital status: Among the 114 patients included in the study: $93(81.6 \%)$ were married. Table 2 outlines their distribution according to marital status.

\section{Sexual dysfunction}

(a) Sexually active patients: Over $80 \%$ of our patients (92) were still sexually active and $19.3 \%$ (22 patients) were no more.

(b) Prevalence of erectile dysfunction: Hemodialysis patients with erectile dysfunction were 98 , representing $86 \%$. Among the 98 patients suffering from erectile dysfunction, 31 (31.6\%) had severe erectile dysfunction.

\section{Determinants of erectile dysfunction}

(a) Univariate analysis

(i)Age and erectile dysfunction: The prevalence of erectile dysfunction increases significantly with age $(\mathrm{p}<0.001)$. Table 3 outlines this correlation.

(ii)Comorbidities and erectile dysfunction: Among comorbidities, only hypertension is associated with the

\begin{tabular}{|l|c|c|}
\hline & Population & Frequency (\%) \\
\hline Single & 12 & 10.5 \\
\hline Married/cohabitation & 93 & 81.6 \\
\hline Divorced & 2 & 1.8 \\
\hline Widower & 7 & 6.1 \\
\hline Total & 114 & 100 \\
\hline
\end{tabular}

Table 2: Patients distribution according to marital status. 


\begin{tabular}{|c|c|c|c|}
\hline Age group & -ED & $+E D$ & $\mathbf{P}$ \\
\hline$\leq 25$ & $3(100.00 \%)$ & $0(0.00 \%)$ & \multirow{7}{*}{$<0.001$} \\
\hline $26-35$ & $4(57.14 \%)$ & $3(42.86 \%)$ & \\
\hline $36-45$ & 4 (15.38\%) & $22(84.62 \%)$ & \\
\hline $46-55$ & 5 (13.16\%) & 33 (86.84\%) & \\
\hline $56-65$ & $0(0.00 \%)$ & $27(100.00 \%)$ & \\
\hline$\geq 66$ & $0(0.00 \%)$ & $13(100.00 \%)$ & \\
\hline Total & 16 (14.04\%) & 98 (85.96\%) & \\
\hline
\end{tabular}

Table 3: Correlation between age and erectile dysfunction.

\begin{tabular}{|c|c|c|c|}
\hline Comorbidities & -ED & + ED & $\mathbf{P}$ \\
\hline \multicolumn{3}{|l|}{ Hypertension } & \multirow{3}{*}{0.001} \\
\hline Present & $9(9.0 \%)$ & $91(91.0 \%)$ & \\
\hline Absent & $7(50.0 \%)$ & $7(50.0 \%)$ & \\
\hline \multicolumn{3}{|l|}{ Diabetes } & \multirow{3}{*}{0,338} \\
\hline Present & $1(6.66 \%)$ & $14(93.3 \%)$ & \\
\hline Absent & $15(15.15 \%)$ & $84(84.84 \%)$ & \\
\hline \multicolumn{3}{|c|}{ Peripheral neuropathy } & \multirow{3}{*}{0.051} \\
\hline Present & $0(0.0 \%)$ & $18(100.0 \%)$ & \\
\hline Absent & $16(16.7 \%)$ & $80(83.3 \%)$ & \\
\hline \multicolumn{3}{|l|}{ Heart disease } & \multirow{3}{*}{0.633} \\
\hline Present & $0(0.0 \%)$ & $3(100.0 \%)$ & \\
\hline Absent & $16(14.4 \%)$ & $95(85.6 \%)$ & \\
\hline \multicolumn{3}{|l|}{ HBP } & \multirow{3}{*}{0.463} \\
\hline Present & $0(0.0 \%)$ & $5(100.0 \%)$ & \\
\hline Absent & $16(14.7 \%)$ & $93(85.3 \%)$ & \\
\hline
\end{tabular}

Table 4: Correlation between co-morbidities and erectile dysfunction.

\begin{tabular}{|c|c|c|c|}
\hline $\begin{array}{l}\text { Seniority in hemodialysis (expressed } \\
\text { in months) }\end{array}$ & -ED & +ED & $\mathbf{P}$ \\
\hline$\leq 12$ & $4(36.36 \%)$ & $7(61.06 \%)$ & \multirow{8}{*}{0.0089} \\
\hline $13-48$ & $10(27.03 \%)$ & $27(72.97 \%)$ & \\
\hline $49-84$ & $0(0.00 \%)$ & $22(100 \%)$ & \\
\hline $85-120$ & $2(7.69 \%)$ & $24(92.31 \%)$ & \\
\hline $121-156$ & $0(0.00 \%)$ & $4(100 \%)$ & \\
\hline $157-192$ & $0(0.00 \%)$ & $7(100 \%)$ & \\
\hline$\geq 193$ & $0(0.00 \%)$ & $7(100 \%)$ & \\
\hline Total & $16(14.04 \%)$ & $98(85.96 \%)$ & \\
\hline
\end{tabular}

Table 5: Seniority in hemodialysis and erectile dysfunction.

\begin{tabular}{|l|c|c|c|}
\hline Depression & -ED & +ED & P \\
\hline No & $15(21.1 \%)$ & $56(78.9 \%)$ & \\
\hline Yes & $1(2.3 \%)$ & $42(97.7 \%)$ & 0.003 \\
\hline Total & $16(14.0 \%)$ & $98(86.0 \%)$ & \\
\hline
\end{tabular}

Table 6: Correlation between depression and erectile dysfunction.

\begin{tabular}{|l|c|c|c|}
\hline \multicolumn{1}{|c|}{} & $\mathbf{T}$ & $\mathbf{P}$ & $\mathbf{9 5 \%}$ IC \\
\hline Testosteronemia & 2.182 & 0.031 & {$[0.09 ; 1.9]$} \\
\hline Rate of LH & 0.869 & 0.397 & {$[-2.5 ; 6.1]$} \\
\hline Rate of FSH & 0.965 & 0.349 & {$[-5.4 ; 14.4]$} \\
\hline
\end{tabular}

Table 7: Correlation between hormonal profile and erectile dysfunction.

\begin{tabular}{|l|c|c|c|}
\hline & $\mathbf{P}$ & OR & $\mathbf{9 5 \%}$ IC \\
\hline Age & $<0.001$ & 1.168 & {$[1.08 ; 1.25]$} \\
\hline Hypertension & $<0.001$ & 10,111 & {$[2.89 ; 35,34]$} \\
\hline Seniority in hemodialysis & 0.008 & 1.024 & {$[1 ; 1.04]$} \\
\hline Depression & 0.022 & 11,250 & {$[1.42 ; 88,56]$} \\
\hline Testosteronemia & 0.038 & 0.74 & {$[0.55 ; 0.98]$} \\
\hline
\end{tabular}

Table 8: Determinants of erectile dysfunction. occurrence of erectile dysfunction ( $\mathrm{p}=0.001$ ). Table 4 highlights this correlation.

(iii)Seniority in hemodialysis and erectile dysfunction: The prevalence of erectile dysfunction increases with seniority in hemodialysis $(\mathrm{p}=0.008)$. Table 5 highlights the correlation between seniority in hemodialysis and erectile dysfunction.

(iv)Depression and erectile dysfunction: The prevalence of erectile dysfunction is higher in hemodialysis patients with depression $(\mathrm{p}=0.003)$. Table 6 highlights the correlation between depression and erectile dysfunction.

(v)Hormonal profile and erectile dysfunction: The prevalence of erectile dysfunction increases significantly with lower testosterone $(p=0.031)$. Table 7 highlights the correlation between hormonal profile and erectile dysfunction.

\section{(b)Multivariate analysis}

In multivariate analysis with logistic regression model, patient's age, hypertension, seniority in hemodialysis, depression and testosteronemia are still associated with onset of erectile dysfunction in hemodialysis patients. Table 8 below highlights this correlation.

\section{Discussion}

\section{Socio-demographic characteristics}

(a) Age: In our study, the patient's mean age was $51.05 \pm 11.66$ years. It is close to the age reported by Aribi et al. in Tunisia estimated at 51.2 years [1]. Several other studies reported similar results. In these various studies, mean age ranged from 48 to 53 years [7,19-23]. Over half of our patients $(57.01 \%)$ were aged between 45 and 65 years. This could be explained by the fact that the prevalence of end stage CKD increases with age, particularly in the case of men [24]. In our study, extreme values of age which were 24 and 75 years are close to those of Aribi et al., Messina et al. and Avakoudjo et al. who respectively recorded 25 and 78 years; 21 and $76 ; 27$ and 78 years $[1,7,9]$ as extreme values. This could be due to the fact that end stage CKD is not only limited to the elderly, as it can also occur at any age.

(b) Marital status: Most respondents were married (81.6\%). This high rate is similar to the studies carried out by Messina et al. and Mumtaz et al. who reported 87.9 and $96.6 \%$ of married patients $[7,21]$. This finding is not surprising as patients included in these different studies are adults as shown by the mean age estimated at 51.18 years.

\section{Sexual dysfunction}

(a) Sexually active patients: Nearly $1 / 5$ of our patients were no more sexually active. It is also the case of studies conducted by Aribi et al. and Tounkara et al. who respectively recorded $26 \%$ and $30 \%$ of sexually inactive patients $[1,25]$. This could be explained by the fact that patients receiving dialysis lose interest in sexual activities due not only to chronic fatigue induced by dialysis but also depression $[11,26]$. Moreover, a large number of the patients were in their sixties. Patient in this age range generally have lower sexual activities.

(b) Prevalence of erectile dysfunction: The prevalence of erectile dysfunction recorded in our study was $86 \%$. This result is similar to those reported in other studies. In fact, in West Africa, Ka et al. in Senegal in 2014 reported $84.9 \%$ prevalence [22]. In Asia: 
Nassir et al. in Saudi Arabia in 2009, Mumtaz et al. in Pakistan in 2009, Malekmakan et al. in Iran in 2011 and Nishida et al. in Japan in 2016 respectively recorded ED prevalence as follows: $82.7 \%, 86 \%, 87.7$ and $90 \%$ [21,27-29].

However, this prevalence is significantly higher than data reported in studies conducted in North Africa. Therefore, Aribi et al. [1] in Tunisia in 2016 and Zbiti et al. in Morocco in 2010 reported respectively $65.21 \%$ and $43.3 \%$ prevalence $[1,10]$. This gap could be explained by the fact that sexuality is considered a taboo subject in these regions. However, the low ED prevalence reported by Zbiti et al. could be attributable to the young age of the study population (mean age $=45 \pm 11.8$ years) and the difference in methodology. In fact, Zbiti et al. did not use International Index of Erectile Function (IIEF) to assess erectile function but rather a subjective estimate of the patients.

\section{Factors associated with erectile dysfunction}

(a) Age: Our study revealed that the more aged the patient, the higher the risk of ED onset. Aribi et al., Kharbach et al., Messina et al., Costa et al., Mumtaz et al., Ka et al., Nassir et al. and Nishida et al. reported the same correlation [1,4,7,20-22,27,29]. In fact, aging is a risk factor for occurrence of atherosclerosis. The latter is part of erectile dysfunction pathogenesis [30]. This could justify the high rate of erectile dysfunction observed in elderly hemodialysis patients.

(b) Hypertension: In our study, hypertension is a risk factor for onset of ED. Aribi et al. reported the same correlation [1]. In fact, erectile dysfunction and hypertension have some pathophysiological mechanisms in common, including atherosclerosis and reduced synthesis of nitric oxide. Moreover, some antihypertensive agents such as $\beta$-blockers, diuretics, central antihypertensive drugs used for these patients are source of erectile dysfunction [30]. This justifies the strong tie between hypertension and erectile dysfunction. However, Kharbach et al., Nassir et al. and Malekmakan et al. did not report any correlation between hypertension and erectile dysfunction $[4,27,28]$.

(c) Seniority in hemodialysis: It emerged from our study that, the longer the hemodialysis period, the higher the risk of ED occurrence. Aribi et al., Kharbach et al. and Nishida et al. reported the same correlation $[1,4,29]$. One of the reasons could be onset of arterial disease which deteriorates progressively [6]. This assumption was confirmed by the results of kidney transplants in early stage of CKD which seem to improve erectile dysfunction [31]. Yet, Messina et al., Ajina et al. and Malekmakan et al. reported no correlation between hemodialysis duration and the onset of erectile dysfunction $[7,8,28]$.

(d)Depression: In this study, depression was closely associated with erectile dysfunction and sexual desire disorder. The same association was reported by Aribi et al. [1] and Coulibaly et al. $[1,32]$. This could be explained by the fact that some neurotransmitters including: Serotonin, norepinephrine and dopamine are involved in not only controlling sexuality in the central stage, but also the onset of depression [33]. As depression is linked to poor transmission of these neurotransmitter systems, it results in sexual function impairment. Therefore, depressive syndrome may lead to sexual dysfunction in patients receiving hemodialysis [34].

In the same vein, sexual disorders induce changed perception of oneself, thereby contributing to onset of depressive symptoms [11]. It is therefore a vicious life-altering condition for the patients.

(e) Testosteronemia: This study revealed significant decrease in testosterone in patients with erectile dysfunction. This result may be explained by the fact that testosterone stimulates the activity of centers involved in urges for sexual activity [33]. Consequently, hypogonadism causes inactivity of these centers resulting in reduced libido. ED is also the result of elimination of androgens trophic and vasodilation effects on the penis. Thus, hypogonadism is a risk factor for erectile dysfunction. Zbiti et al. and Kharbach et al. $[4,10]$ reached the same conclusion.

Unlike our study and that of Zbiti et al. and Kharbach et al. reported a correlation between the elevation of serum gonadotropins and sexual disorders $[4,10]$.

\section{Determinants of erectile dysfunction}

In multivariate analysis: Patient's age, hypertension, seniority in hemodialysis, depression and testosteronemia are still associated with onset of erectile dysfunction in patients receiving hemodialysis. In fact, our study revealed that testosterone is a protective factor against erectile dysfunction: The risk of erectile dysfunction onset increases with reduced testosterone. Furthermore, hemodialysis patients with depression and hypertension are respectively 11.25 and 10.11 times more exposed to the risk of developing erectile dysfunction.

\section{Conclusion}

$\mathrm{CKD}$ and hemodialysis have significant impact in several areas of patient's life. Sexuality is one of the most affected aspects. It is obvious from this study that prevalence of sexual dysfunction is very high in hemodialysis patients. All aspects of sexual function are affected. Determinants of erectile dysfunction were: Age, hypertension, seniority in hemodialysis, depression and lower testosterone. Very few hemodialysis patients discussed their sexual problems with a health officer in view of receiving convenient treatment. Sexual dysfunction must therefore be considered as a major factor impacting on patient's quality of life, and there is need to include care and support in treatment strategies. It's important to advance this study in a larger sample size including women receiving hemodialysis.

\section{Acknowledgment}

We thank the authorities of the teaching hospital CNHU-HKM and the department of medicine and medical specialties for having made this work possible.

\section{References}

1. Aribi L, Masmoudi R, Houidi AB, Charfeddine F, Jarraya F, et al. (2015) Sexual disorders in hemodialysis patients. Med Tunisia 93: 79-84.

2. Ene-lordache B, Perico N, Bikbov B, Carminati S, Remuzzi A, et al. (2016) Chronic kidney disease and cardiovascular risk in six regions of the world (ISNKDDC): A cross-sectional study. Lancet Glob Health 4: 307-319.

3. Ouattara B, Kra O, Diby K, Thot'o As, Ouattara I (2004) A retrospective study on the incidence of chronic renal failure in the department of internal medicine and nephrology of the University Hospital Center of Antananarivo. Afr Biomed 9: 66-70.

4. Kharbach Y, Bourouhou H, Tenkorang S, Mellasa S, Ammari JE, et al. (2016) Correlations between sexual dysfunction and the clinico-biological profile of renal failure in hemodialysis. Afr J Urol 22: 310-314.

5. Giuliano F (2013) Recommended questionnaires in sexual medicine. Prog Uro 23: 811- 821.

6. Kleinclauss F, Kleinclauss C, Bittard H (2005) Erectile dysfunction in patients with renal insufficiency. Prog Urol 15: 447-456. 
Citation: Agboton BL, Avakoudjo J, Azonbakin S, Hazoume R, Tossoulegue A, et al. (2017) Determinants of Erectile Dysfunction in Hemodialysis Patients in CNHU-HKM, Cotonou. J Kidney 3: 159. doi: 10.4172/2472-1220.1000159

7. Messina LE, Claro JA, Nardozza A, Andrade E, Ortiz V et al. (2007) Erectile dysfunction in patients with chronic renal failure. Int Braz J Urol 33: 673-678.

8. 8. Ajina M, Zaouali M, Loussaief W, Benjamaa N, Boughizane S, et al. (2011) Analysis of spermatic, erectile and hormonal status in hemodialysis patients. Basic Clin Androl 21: 186-191.

9. Avakoudjo J, Paré A, Vigan J, Gandaho I, Hounasso P, et al. (2012) Erectile dysfunction in hemodialysis patients at CNHU-HKM, Cotonou: Epidemiological profile. Basic Clin Androl 22: 246-251.

10. Zbiti N, Benrais N, Mohamed AO, Hamzaoui H, Rhou H, et al. (2010) Gonadal disorders in chronic male hemodialysis. J Maroc Urol 22: 11-13.

11. Toorians AWF, Janssen E, Laan E, Gooren LJG, Giltay EJ, et al. (1997) Chronic renal failure and sexual functioning: Clinical status versus objectively assessed sexual response. Nephrol Dial Transplant 12: 2654-2663.

12. Kaufman JM, Hatzichristou DG, Mulhall JP, Fitch WP, Goldstein I (1994) Impotence and chronic renal failure : A study of the hemodynamic pathophysiology. J Urol 151: 612-618.

13. Rosen RC, Riley A, Wagner G, Osterloh IH, Kirkpatrick J, et al. (1997) The international index of erectile function (IIEF): A multidimensional scale for assessment of erectile dysfunction. Urology 49: 822-830.

14. Kroenke K, Spitzer RL, Williams JB (2001) The PHQ-9: Validity of a brie depression severity measure. J Gen Intern Med 16: 606-613.

15. Lowe B, Spitzer RL, Grafe K, Kroenke K, Quenter A, et al. (2004) Comparative validity of three screening questionnaires for DSM-IV depressive disorders and physicians diagnoses. J Affect Disord 78: 131-140.

16. Kung S, Alarcon RD, Frye MA (2013) Comparing the beck depression inventoryII (BDI-II) and patient health questionnaire (PHQ-9) depression measures in an integrated mood disorders practice. J Affect Disord 145: 341-343.

17. Genton L, Majno P, Raguso C, Hans DB, Pichard C (2002) Integration of nutritional assessment with the medical examination upon admission to the hospital. Réanimation 11: 392-405.

18. Bonnet F, Laville M (2005) Metabolic syndrome: Definition, epidemiology, complications. Spectra biologie 145: 27-29.

19. Yayo SE, Diafouka F, Hauhouot-Attoungbre ML, Ake-Edjeme A, Ahibo $H$, et al. (2008) Alteration of the pituitary-gonadal axis in male African chronic renal failure. Immunoana spécial bio 23: 54-57.

20. Costa MR, Reis AM, Pereira BP, Ponciano VC, de Oliveira EC (2014) Associated factors and prevalence of erectile dysfunction in hemodialysis patients. Int Braz J Urol 40: 44-55.
21. Mumtaz A, Anees M, Barki MH, Sami W, Hussain S, et al. (2009) Erectile dysfunction in haemodialysis patients. J Ayub Med Coll Abbottabad 21: 4-7.

22. Ka EF, Seck SM, Cisse MM, Lemraboot AT, Faye M, et al. (2014) Erectile dysfunction in chronic hemodialysis patients in dakar: A cross-sectional study in 2012. Nephrourol Mon 6: e21138

23. Gorsane I, Amri N, Younsi F, Helal I, Kheder I (2016) Erectile dysfunction in hemodialysis patients. Saudi J Kid Dis Transplant 27: 23-28.

24. Thuret R, Timsit MO, Kleinclauss $F(2016)$ Chronic renal failure and rena transplantation. Prog urol 26: 882-908.

25. Tounkara AA, Coulibaly AMS, Diakité ML, Coulibaly N, Sissoko I, et al. (2016) Prevalence of erectile dysfunction among chronic hemodialysis patients in the nephrology and hemodialysis department of the Point G. CHU. Uro'Andro 1 297-300.

26. Palmer BF (1999) Sexual dysfunction in uremia. J Am Soc Nephrol 10: 1381 1388.

27. Nassir A (2010) Erectile dysfunction risk factors for patients entering dialysis programme. Andrologia 42: 41-47.

28. Malekmakan L, Shakeri S, Haghpanah S, Pakfetrat M, Sarvestani AS, et al. (2011) Epidemiology of erectile dysfunction in hemodialysis patients using IIEF questionnaire. Saudi J Kid Dis Transplant 22: 232-236.

29. Nishida H, Yamagishi A, Sakurai T, Shibasaki T, Kawazoe H, et al. (2016) Risk factors for erectile dysfunction in end-stage renal disease patients with short or long term hemodialysis therapy. Ren Replace Ther 2: 65-69

30. El Ammari JE, Riyach O, Ahallal Y, Tabiri Y, Mellas S, et al. (2012) Physiology and physiopathology of erection. Med Esperance 19: 72-77.

31. Ayub W, Fletcher S (2000) End-stage renal disease and erectile dysfunction. Is there any hope? Nephrol Dial Transplant 15: 1525-1528

32. Coulibaly G, Goumbri P, Ouédraogo N, Dabilgou A, Napon C, et al. (2016) Factors associated with depressive symptoms in chronic hemodialysis patients of centre hospitalier universitaire Yalgado Ouédraogo (Burkina Faso). Néphrol Ther 12: 210-214.

33. Cour F , Droupy S, Faix A, Methorsta C, Giuliano F (2013) Anatomy and physiology of sexuality. Prog Urol 23: 547-561.

34. Steele TE, Wuerth D, Finkelstein S, Juergensen D, Juergensen P, et al. (1996) Sexual experience of the chronic peritoneal dialysis patient. J Am Soc Nephrol 7: 1165-1168. 